\title{
ANALISIS AKTIVITAS BELAJAR SISWA BERDASARKAN GAYA BELAJAR VISUAL AUDITORIAL KINESTETIK SISWA PADA PEMBELAJARAN BIOLOGI KELAS XI IPA MAN 1 MEDAN
}

\section{ANALYSIS OF STUDENT LEARNING ACTIVITY BASED ON VISUAL AUDITORY KINESTHETIC LEARNING STYLES ON BIOLOGY STUDY XI IPA CLASS MAN1 MEDAN}

\author{
Siti Rizka Amina* dan Zulkifli Simatupang \\ Program Studi Pendidikan Biologi, FMIPA, Universitas Negeri Medan, Medan \\ Jl. Willem Iskandar Psr. V Medan Estate, Medan, Indonesia, 20221 \\ *E-mail : rizkaamina@gmail.com
}

\begin{abstract}
ABSTRAK
Penelitian ini bertujuan untuk mengetahui aktivitas belajar siswa berdasarkan gaya belajar visual auditorial dan kinestetik siswa pada pembelajaran biologi kelas XI IPA MAN 1 Medan Tahun Pembelajaran 2015/2016. Dengan jumlah populasi yaitu 60 siswa kelas XI IPA MAN 1 Medan. Sampel ditentukan dengan menggunakan teknik purposive sampling dimana sampel berjumlah 18 siswa. Jenis penelitian yang digunakan dalam penelitian ini merupakan penelitian deskriptif, dengan instrumen penelitian berupa angket sebanyak 36 butir dan lembar observasi aktivitas belajar yang dilakukan sebanyak 2 kali pengamatan. Dari hasil penelitian diketahui bahwa siswa dengan gaya belajar visual memiliki aktivitas menulis tertinggi dengan presentase sebesar $51,1 \%$, aktivitas melihat yakni sebesar $50 \%$ dan aktivitas motorik tertinggi dengan presentase sebesar $39,1 \%$. Siswa dengan gaya belajar auditorial memiliki aktivitas mendengar yang tinggi dengan presentase sebesar $37,9 \%$ dan aktivitas berbicara dengan presentase sebesar $32,7 \%$. Siswa dengan gaya belajar kinestetik memiliki aktivitas belajar tertinggi yaitu aktivitas berbicara dengan presentase sebesar $41,4 \%$, aktivitas mendengar dengan presentase sebesar 39,9\%.
\end{abstract}

Kata kunci: aktivitas belajar biologi, gaya belajar

\section{ABSTRACT}

This research aims to determine students's learning activities based on visual, auditory and kinesthetic learning styles of students XI IPA class at MAN 1 Medan Academic Year 2015/2016. The Population of this research is 60 students in two of XI IPA classes and samples were determined by using purposive sampling technique in which the sample was 18 students. The type of this research is a descriptive research. As the research instrument with 36 item of learning style's questionnaire and the observations are done two times by using learning activities observation sheets. The survey results revealed that students with visual learning style have the highest writing activities with a percentage of $51.1 \%$, visual activities by $50 \%$ and motor activities with a percentage of $39.1 \%$. Students with auditory learning style have a high listening activities with a percentage of $37.9 \%$ and oral activities with a percentage of $32.7 \%$. Students with kinesthetic learning style have the highest oral activities with a percentage of $41.4 \%$, and listening activities with a percentage of $39.9 \%$.

Keywords: biology learning activities, learning styles

\section{PENDAHULUAN}

Setiap individu memiliki karakter tersendiri dalam mengembangkan cara belajarnya dan daya pikir dalam menyelesaikan sebuah permasalahan yang dihadapi. Menurut Hasruddin dan Rezeqi (2012), mengajarkan ilmu kepada siswa dikatakan baik jika memenuhi kriteria, yaitu sesuai dengan hakikat ilmu itu dan sesuai dengan pengetahuan tentang bagaimana siswa belajar. Karakteristik yang dimiliki setiap siswa tersebut juga ditegaskan dalam Permendiknas No. 41 Tahun 2007 (Kurikulum 2006) dan Permendikbud No. 22 Tahun 2016 (Kurikulum 2013) tentang Standar Proses Pendidikan Dasar dan Menengah, yang mengisyaratkan bahwa dalam proses pembelajaran, seorang guru seyogyanya dapat 
memperhatikan karakteristik siswanya. Karakteristik siswa sesungguhnya memiliki cakupan yang luas. Salah satu karakteristik siswa yang perlu diperhatikan guru dan akan mewarnai terhadap efektivitas belajar dan pembelajaran yaitu berkenaan dengan gaya belajar siswa.

Gaya belajar merupakan suatu kombinasi dari bagaimana seseorang menyerap dan kemudian mengatur serta mengolah informasi. Gaya belajar bukan hanya berupa aspek ketika menghadapi informasi, melihat, mendengar, menulis dan berkata tetapi juga aspek pemrosesan informasi sekunsial, analitik, global atau otak kiri dan otak kanan. Aspek lain adalah ketika merespon sesuatu atas lingkungan belajar (diserap secara abstrak dan konkret). Terdapat tiga tipe gaya belajar yang akan dibahas dalam penelitian, yaitu visual (cenderung belajar melalui apa yang mereka lihat), auditorial (belajar melalui apa yang mereka dengar) dan kinestetik (belajar melalui gerak dan sentuhan) (Hasrul, 2009).

Para peneliti menemukan adanya berbagai gaya belajar yang dapat digolongkan menurut kategori tertentu. Mereka berkesimpulan bahwa, (1) Tiap siswa belajar menurut cara sendiri yang kita sebut gaya belajar; (2) Kita dapat menemukan gaya belajar tersebut dengan instrumen tertentu; (3) Kesesuaian gaya mengajar dengan gaya belajar mempertinggi efektivitas belajar. Informasi tentang adanya gaya belajar yang berbeda-beda mempunyai pengaruh atas kurikulum, administrasi, dan proses belajar-mengajar. Dengan mengetahui gaya belajar siswa, guru dapat menyesuaikan gaya mengajar dengan kebutuhan siswa, misalnya dengan menggunakan berbagai gaya mengajar sehingga seluruh siswa dapat memperoleh cara yang efektif baginya. Khususnya jika akan dijalankan pengajaran individual, gaya belajar siswa perlu diketahui (Nasution, 2010).

Berdasarkan hal diatas, adapun tujuan penelitian ini adalah untuk mengetahui aktivitas belajar biologi siswa berdasarkan gaya belajar visual auditorial kinestetik siswa kelas XI IPA MAN 1 Medan T.P 2014/2015.

\section{METODE PENELITIAN}

Penelitian ini dilaksanakan di MAN 1 Medan yang beralamat JI. Willem Iskandar no. 7B, Kode Pos 20222. Waktu penelitian dilakukan pada bulan April sampai dengan Juni 2016. Jenis penelitian ini merupakan penelitian deskriptif, yakni penelitian yang dilaksanakan dengan tujuan memberi suatu gambaran dari aktivitas belajar siswa pada pembelajaran biologi dengan berbagai strategi dan metode yang digunakan guru selama pengamatan berlangsung berdasarkan tipe gaya belajar visual, auditorial dan kinestetik siswa.

Populasi dalam penelitian ini adalah seluruh siswa yang ada di dua kelas XI IPA MAN 1 Medan Tahun Pembelajaran 2015/2016 yang terdiri dari 60 siswa. Sampel penelitian ditetapkan 30\% dari total populasi (Arikunto, 2006). Penetapan sampel dipilih dengan menggunakan teknik purposive sampling yakni penarikan sampel berdasarkan siswa dengan tipe gaya belajar visual, auditorial, kinestetik masing-masing 6 siswa dan mengabaikan siswa yang tidak termasuk kriteria yang ditentukan sehingga jumlah seluruh sampel adalah 18 sampel.

Langkah-langkah dalam penelitian ini terdiri atas tahapan persiapan, pelaksanaan, dan pengumpulan data dan pengolahan data. Tahap persiapan meliputi observasi awal ke sekolah MAN 1 Medan dan meminta izin kepada pihak sekolah untuk melakukan penelitian di sekolah tersebut. Kemudian membuat proposal penelitian dan memvalidasi angket gaya belajar kepada validator ahli. Tahap selanjutnya dalam penelitian yaitu pelaksanaan dengan menyebarkan angket gaya belajar dan mengkalkulasikan hasilnya, kemudian melaksanakan pengumpulan data aktivitas belajar biologi dengan menggunakan lembar pengamatan aktivitas siswa. Tahap berikutnya yaitu melakukan pengolahan data dengan menghitung jumlah aktivitas belajar biologi siswa dengan gaya belajar visual, auditorial dan kinestetik. Tahap terakhir yaitu melakukan analisis data terhadap hasil penelitian dan menarik kesimpulan.

Instrumen yang digunakan dalam penelitian ini yaitu angket tertutup gaya belajar VAK dengan dua pilihan jawaban (ya/tidak) sebanyak 36 butir dan lembar pengamatan 
aktivitas belajar siswa berdasarkan gaya belajar VAK. Untuk menentukan tipe gaya belajar siswa diperoleh dengan menjumlahkan skor jawaban ya pada lembar angket gaya belajar dimana skor dengan jumlah terbanyak merupakan gaya belajar paling dominan. Dan untuk menentukan apasaja aktivitas belajar biologi siswa diperoleh dengan menjumlahkan skor dari masing-masing aktivitas belajar yang terdapat pada lembar pengamatan dan diolah dengan rumus deskriptif presentase sebagai berikut:

$$
P=\frac{F}{N} \times 100 \%
$$

Keterangan :

$\mathrm{P}=$ Angka persentase satu jenis aktivitas belajar $\mathrm{F}=$ Jumlah aktivitas satu kategori gaya belajar $\mathrm{N}=$ Jumlah aktivitas pada semua kategori gaya belajar

\section{HASIL PENELITIAN}

\section{Deskripsi Hasil Penelitian Gaya Belajar Siswa Hasil} Pengumpulan Data Menggunakan Angket

Berdasarkan hasil penelitian angket gaya belajar terhadap siswa XI IPA MAN 1 Medan T.P. 2015/2016 dapat dilihat pada Tabel 1 berikut.

Tabel 1. Presentase Gaya Belajar Siswa XI IPA MAN

\begin{tabular}{clc}
\multicolumn{3}{c}{ 1 Medan } \\
\hline No. & Gaya Belajar & Jumlah Siswa (\%) \\
\hline 1. & Visual & $33,3 \%$ \\
2. & Auditorial & $20 \%$ \\
3. & Kinestetik & $46,7 \%$ \\
\hline
\end{tabular}

Jumlah presentase tertinggi gaya belajar siswa kelas XI IPA MAN 1 Medan T.P. 2015/2016 adalah siswa dengan kategori gaya belajar kinestetik yaitu dengan presentase sebesar $46,7 \%$ diikuti dengan gaya belajar visual dengan presentase sebesar 33,3\%. Hasil penelitian ini memberikan gambaran, bahwa siswa kelas XI IPA MAN 1 Medan T.P 2015/2016 cenderung memiliki karakteristik masukan awal dalam hal gaya belajar, yakni gaya belajar kinestetik.

\section{Deskripsi Hasil Penelitian Aktivitas Belajar Biologi Siswa Berdasarkan Gaya Belajar VAK}

Berdasarkan hasil penelitian terhadap lembar aktivitas belajar biologi siswa XI IPA MAN 1 Medan
T.P. 2015/2016 dengan intensitas pengamatan sebanyak 2 x 90 menit, dapat dilihat pada Tabel 2 berikut.

Tabel 2. Persentase Aktivitas Belajar Siswa Visual Kelas XI IPA MAN 1 Medan

\begin{tabular}{clc}
\hline No. & \multicolumn{1}{c}{ Aktivitas Belajar } & $\begin{array}{c}\text { Siswa } \\
\text { Visual }\end{array}$ \\
\hline 1. & Aktivitas melihat & $50 \%$ \\
2. & Aktivitas mendengar & $22,15 \%$ \\
3. & Aktivitas berbicara & $25,9 \%$ \\
4. & Aktivitas menulis & $51,11 \%$ \\
5. & Aktivitas menggambar & $0 \%$ \\
6. & Aktivitas motorik & $39,13 \%$ \\
\hline
\end{tabular}

Berdasarkan Tabel 2 dapat diketahui presentase jumlah aktivitas belajar tertinggi pada siswa dengan kecenderungan gaya belajar visual adalah aktivitas menulis dengan presentase sebesar $51,1 \%$, aktivitas melihat sebesar $50 \%$, dan aktivitas motorik dengan presentase sebesar $39,1 \%$.

Tabel 3. Persentase Aktivitas Belajar Siswa Auditorial Kelas XI IPA MAN 1 Medan

\begin{tabular}{clc}
\hline No. & \multicolumn{1}{c}{ Aktivitas Belajar } & $\begin{array}{c}\text { Siswa } \\
\text { Auditorial }\end{array}$ \\
\hline 1. & Aktivitas melihat & $22,03 \%$ \\
2. & Aktivitas mendengar & $37,97 \%$ \\
3. & Aktivitas berbicara & $32,67 \%$ \\
4. & Aktivitas menulis & $26,67 \%$ \\
5. & Aktivitas menggambar & $0 \%$ \\
6. & Aktivitas motorik & $30,43 \%$ \\
\hline
\end{tabular}

Berdasarkan Tabel 3 dapat diketahui bahwa siswa dengan kecenderungan gaya belajar auditorial memiliki kemunculan aktivitas belajar tertinggi yaitu aktivitas mendengar dengan presentase sebesar 37,9\%, aktivitas berbicara dengan presentase sebesar $32,7 \%$ dan aktivitas motorik sebesar $30,4 \%$. 
Tabel 4. Persentase Aktivitas Belajar Siswa Kinestetik Kelas XI IPA MAN 1 Medan

\begin{tabular}{clc}
\hline No. & \multicolumn{1}{c}{ Aktivitas Belajar } & $\begin{array}{c}\text { Siswa } \\
\text { Kinestetik }\end{array}$ \\
\hline 1. & Aktivitas melihat & $27,97 \%$ \\
2. & Aktivitas mendengar & $39,87 \%$ \\
3. & Aktivitas berbicara & $41,43 \%$ \\
4. & Aktivitas menulis & $22,22 \%$ \\
5. & Aktivitas menggambar & $0 \%$ \\
6. & Aktivitas motorik & $30,43 \%$ \\
\hline
\end{tabular}

Berdasarkan Tabel 4 dapat diketahui bahwa siswa dengan kecenderungan gaya belajar kinestetik memiliki aktivitas belajar tertinggi yaitu aktivitas berbicara dengan presentase sebesar $41,4 \%$, aktivitas mendengar dengan presentase sebesar $39,9 \%$ dan aktivitas motorik sebesar $30,4 \%$.

\section{PEMBAHASAN}

\section{Analisis Aktivitas Belajar Siswa Berdasarkan Gaya Belajar VAK Kelas XI IPA MAN 1 Medan}

Berdasarkan data hasil penelitian dengan menggunakan angket gaya belajar VAK dapat diketahui bahwa siswa kelas XI IPA MAN 1 Medan Tahun Pembelajaran 2015/2016 memiliki kecenderungan gaya belajar kinestetik. Namun berdasarkan lembar pengamatan aktivitas belajar pada saat proses pembelajaran berlangsung, jumlah aktivitas siswa dengan gaya belajar kinestetik cenderung rendah dibandingkan dengan kedua gaya belajar siswa lainnya. Hal ini menunjukkan bahwa pembelajaran yang diterapkan belum sepenuhnya dapat memfasilitasi aktivitas siswa XI IPA MAN 1 Medan T.P 2015/2016 dengan karakteristik masukan awal kinestetik.

Aktivitas belajar yang muncul dalam pembelajaran Biologi di kelas XI IPA MAN 1 Medan berdasarkan pembelajaran yang diterapkan pada saat pengamatan berlangsung menggunakan metode ekspositori yakni metode yang menggabungkan antara ceramah dan tanya jawab antar guru dan murid yang dilakukan sepanjang waktu pembelajaran serta pembelajaran presentasi oleh siswa secara berkelompok. Hal ini menyebabkan kemunculan aktivitas menggambar sebesar $0 \%$ saat dilakukan pengamatan terhadap siswa dengan semua kategori gaya belajar.

\section{Analisis Aktivitas Belajar Siswa dengan Gaya Belajar Visual}

Hasil pengolahan data menerangkan bahwa aktivitas belajar yang dilakukan oleh siswa dengan gaya belajar visual memiliki kecenderungan aktivitas menulis yang tinggi. Aktivitas menulis tersebut antara lain mencatat penjelasan guru, mencatat dari papan tulis serta menjawab pertanyaan dengan menulis di papan tulis. Aktivitas menulis lebih dominan dilakukan oleh siswa yang termasuk kategori gaya belajar visual. Hal ini sesuai dengan Russel (2011) yang menyatakan bahwa anak dengan kategori gaya belajar visual cenderung akan banyak menulis catatan agar dapat melihatnya kembali nanti. Djamarah (2011) mengungkapkan walaupun pada waktu tertentu seseorang harus mendengarkan isi ceramah, namun dia tidak bisa mengabaikan masalah mencatat hal-hal yang dianggap penting. Hal ini didukung oleh penelitian yang dilakukan oleh Bire (2014) yang mengemukakan bahwa seseorang yang bertipe visual akan cepat mempelajari bahan-bahan yang disajikan secara tertulis, bagan, grafik atau gambar atau dengan kata lain lebih mudah mempelajari bahan pelajaran yang dapat dilihat dengan alat penglihatannya.

\section{Analisis Aktivitas Belajar Siswa dengan Gaya Belajar Auditorial}

Siswa dengan kategori gaya belajar auditorial memiliki aktivitas mendengar yang tinggi yakni antara lain aktivitas mendengarkan ceramah atau penjelasan guru, mendengarkan percakapan atau diskusi serta mendengarkan presentasi. Berdasarkan hal ini, siswa dengan gaya belajar auditorial artinya lebih mengandalkan indera pendengarannya untuk dapat mengingat dan memahami pembelajaran dengan baik. Aktivitas mendengar oleh siswa dengan gaya belajar auditorial dapat dilihat dari kecenderungan mereka dalam berkonsentrasi mendengarkan dengan respon mengangguk atau menanggapi dengan ikut tertawa bila guru menjelaskan dengan candaan, tanpa melakukan aktivitas lain. Telah diketahui bahwa pada saat pengamatan, pembelajaran yang diterapkan adalah metode ceramah dan presentasi oleh siswa menggunakan 
Power Point. Dan diketahui bahwa kedua metode pembelajaran ini menuntut siswa sebagai subyek belajar untuk mengandalkan pendengaran mereka agar dapat mengikuti pembelajaran. Hal ini sesuai dengan DePorter (2013) dimana karakteristik siswa auditorial yang memiliki kecenderungan penyerapan alami dengan mengandalkan indra pendengaran untuk bisa memahami pembelajaran.

Aktivitas mendengar dan berbicara cenderung dilakukan oleh siswa dengan gaya belajar kategori auditorial hal ini sesuai dengan penelitian yang dilakukan oleh Lestari (2012) yang menyatakan bahwa siswa auditorial cenderung sebagai pembicara yang baik. Mereka mudah belajar dengan mendiskusikan dengan orang lain tentang suatu materi tertentu. Dalam kegiatan pembelajaran yang berdasarkan gaya belajar auditorial, siswa membutuhkan suasana yang bisa mengoptimalkan kemampuan pendengaran mereka. Salah satu cara adalah dengan memberikan kesempatan berdiskusi dalam kelompok dan menyajikan temuan-temuanya.

\section{Analisis Aktivitas Belajar Siswa dengan Gaya Belajar Kinestetik}

Berdasarkan hasil penelitian, aktivitas belajar dengan presentase tertinggi yang dimiliki siswa dengan kategori gaya belajar kinestetik adalah aktivitas berbicara atau oral activities. Aktivitas berbicara yang dilakukan antara lain, bertanya, menghapal materi serta berdiskusi dengan teman. Russel (2011) mengemukakan bahwa para pembelajar dengan kecenderungan kinestetik akan menjadi seorang yang banyak berbicara, karena berbicara merupakan bentuk dari gerakan.

Pada saat pengamatan berlangsung didapatkan siswa kinestetik cenderung melakukan aktivitas selain dari kelima aktivitas yang mendukung pembelajaran yang diteliti. Banyak faktor yang menyebabkan siswa kinestetik cenderung melakukan aktivitas lain yang tidak berkenaan dengan pembelajaran, khususnya pada saat pengamatan, pembelajaran metode yang diterapkan yakni metode ceramah dan presentasi materi oleh siswa menggunakan Power Point yang dalam hal ini siswa sebagai subyek belajar dituntut untuk banyak melakukan aktivitas mendengar sambil duduk diam di kursi masing-masing. Menurut Russel (2011) Seseorang yang memiliki kecenderungan kinestetik lebih suka belajar dengan bekerja. Duduk diam dalam waktu yang lama adalah hal yang sulit dilakukan. Berdasarkan hal ini dapat diketahui bahwa siswa kinestetik membutuhkan lebih banyak aktivitas belajar yang mendukung penyerapan alami mereka yakni belajar melalui sentuhan atau percobaan langsung agar dapat mengikuti dan memahami pembelajaran dengan baik.

\section{SIMPULAN}

Berdasarkan hasil penelitian maka kesimpulan dalam penelitian analisis aktivitas belajar biologi siswa dari yang tertinggi sampai dengan yang terendah berdasarkan gaya belajar VAK siswa kelas XI IPA MAN 1 Medan T.P. 2015/2016 adalah siswa visual memiliki aktivitas belajar yaitu, aktivitas menulis, aktivitas melihat dan aktivitas motorik. Siswa auditorial memiliki aktivitas belajar yaitu, aktivitas mendengar, aktivitas berbicara dan aktivitas motorik. Siswa kinestetik memiliki aktivitas belajar yaitu, aktivitas berbicara, aktivitas mendengar dan aktivitas motorik.

\section{UCAPAN TERIMA KASIH}

Ucapan terima kasih penulis ucapkan kepada Bapak Kepala Sekolah MAN 1 Medan, kepada Ibu guru Biologi Dra. Herawati D, S.Ag. yang telah membantu serta seluruh siswa di MAN 1 Medan.

\section{DAFTAR PUSTAKA}

Arikunto S. 2006. Prosedur Penelitian Suatu Pendekatan Praktek. Jakarta: Rineka Cipta.

Bire AL. 2014. Pengaruh Gaya Belajar Visual, Auditorial, dan Kinestetik Terhadap Prestasi Belajar Siswa. Jurnal Kependidikan. 44(2): 168-174

DePorter B. dan Hernacki M. 2013. Quantum Learning, Membiasakan Belajar Nyaman dan Menyenangkan. Bandung: Kaifa

Djamarah SB. 2011. Psikologi Belajar. Jakarta: Rineka Cipta 
Halaman : $355-360$

Hasruddin dan Rezeqi S. 2012. Analisis Pelaksanaan Praktikum Biologi dan Permasalahannya di SMA Negeri Sekabupaten Karo. Jurnal Tabularasa PPS UNIMED. 9(1): 17-32

Hasrul. 2009. Pemahaman Tentang Gaya Belajar. Jurnal MEDTEK. 1(2): 1-9

Lestari A. 2012. Penerapan Strategi Pembelajaran Matematika Berbasis Gaya Belajar VAK (Visual Auditorial Kinestetik). Jurnal Pendidikan Matematika. 1(1): 1-7

Nasution S. 2010. Berbagai Pendekatan dalam Proses Belajar Mengajar. Bandung: Bumi Aksara

Russel L. 2011. The Accelerated Learning Fieldbook, Panduan Belajar Cepat untuk Pelajar dan Umum. Bandung: Nusa Media. 